\title{
Gold-Colored Organic Crystals Formed from an Azobenzene Derivative
}

\author{
Akiko Matsumoto ${ }^{1}$, Maho Kawaharazuka ${ }^{1}$, Yutaka Takahashi ${ }^{1}$, Norio Yoshino ${ }^{1}$, \\ Takeshi Kawai ${ }^{1,2}$ and Yukishige Kondo ${ }^{1,2 *}$ \\ ${ }^{1}$ Department of Industrial Chemistry, Faculty of Engineering, Tokyo University of Science (12-1 Ichigaya-funagawara, Shinjuku, Tokyo 162- \\ 0826, JAPAN) \\ ${ }^{2}$ Center for Colloid and Interface Science (CCIS), Tokyo University of Science (1-3 Kagurazaka, Shinjuku, Tokyo 162-8601, JAPAN)
}

\begin{abstract}
The azobenzene derivative 4,4'-bis $\{1-[2-(N, N$-dimethylamino $)]$ ethoxy $\}$ azobenzene has been found to form gold-colored plate-like crystals. The thin film obtained by accumulating the crystals has a maximum specular reflectance of ca. $15 \%$ for visible light. To investigate the structure of the gold-colored crystals, UV-vis, X-ray diffraction (XRD), and IR analyses were performed. UV-vis measurements show that the molecules in the crystal produce J-aggregates. Furthermore, XRD measurements estimated the long-range $d$-spacing for the crystal as $1.51 \mathrm{~nm}$. These results indicate that the azobenzene moieties are oriented diagonally against the crystal surfaces. When the crystals are placed in a desiccator (humidity $40 \%$ ) for $1 \mathrm{~d}$, their color changes from gold to yellow. IR measurements show that the gold-colored crystals contain crystallized water, while there are no water molecules in the yellow crystals, in which the structure of the J-aggregates is disrupted. These results show that the crystallized water molecules are essential for the formation of the J-aggregates and the resultant gold luster.
\end{abstract}

Key words: gold crystal, azobenzene, J-aggregate, thin film

\section{INTRODUCTION}

It is no exaggeration to say that the pursuit of technologies to create noble metals, such as gold and silver, from base metals-that is, alchemy-has greatly contributed to the development of modern chemistry. In particular, gold has long fascinated people since ancient times because of its worth and beauty. In fact, gold-colored origami is the most popular form of origami among Japanese children who practice creating origami figures by folding colored papers available in commercial origami sets. Recently, we succeeded in preparing gold-colored organic crystals from the azobenzene derivative 4,4'-bis $\{1-[2-(N, N$-dimethylamino)] ethoxyłazobenzene (1) (Chart 1). Although some polymers are known to be golden in color ${ }^{1)}$, there have been very few reports concerning gold-colored low molecular weight (MW) materials. To the best of our knowledge, the only reports on gold-colored materials have been from research by Ogura et $a l^{2-4}{ }^{2-4}$. They reported that crystals of $\pi$-conjugated compounds with a thiophene-pyrrole-thiophene chemical skeleton produce a gold color ${ }^{5}$.

The aggregation of azobenzene derivatives has been extensively studied, and they have been found to form layers of J-aggregates or $\mathrm{H}$-aggregates on solid substrates ${ }^{6,77}$. However, most of these studies were limited to the photoisomerization of several layers consisting of J- or H-aggregates; there are no reports on the color of crystals formed by stacking of a number of monolayers formed from the Jaggregates of an azobenzene derivative. We describe here a novel low MW compound-denoted here as 1-that forms gold-colored crystals by the accumulation of many J-aggregate layers of 1 and demonstrate that crystallized water molecules in the crystals of 1 play an important role in

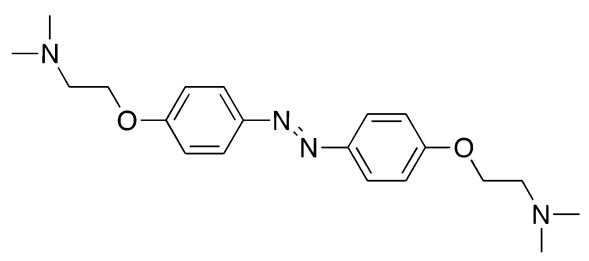

Chart 1 4,4'-Bis $\{1-[2-(N, N$-dimethylamino)]ethoxy\}azoben zene (1) Forming Gold-colored Crystals with Water Molecules.

\footnotetext{
*Correspondence to: Yukishige Kondo, Department of Industrial Chemistry, Faculty of Engineering, Tokyo University of Science, 12-1 Ichigaya-funagawara, Shinjuku, Tokyo 162-0826, JAPAN

E-mail: ykondo@ci.kagu.tus.ac.jp

Accepted October 23, 2009 (received for review September 9, 2009)

Journal of Oleo Science ISSN 1345-8957 print / ISSN 1347-3352 online

http://www.jstage.jst.go.jp/browse/jos/
} 
bringing about the gold color. Azobenzene derivatives are widely used as dyes and pigments. We believe that this report is the first to suggest that nanoscale spatial control of azobenzene derivative aggregation produces new colors that have never been seen before in conventional use.

\section{EXPERIMENTAL}

\subsection{Materials}

p-Aminophenol, $\mathrm{NaNO}_{2}$, conc. $\mathrm{HCl}$, hydroxyammonium chloride, $\mathrm{CuSO}_{4} \cdot 5 \mathrm{H}_{2} \mathrm{O}, 28 \% \mathrm{NH}_{3}$ aq., $\mathrm{K}_{2} \mathrm{CO}_{3}, 1,2$-dibromoethane, acetone, $40 \%$ dimethylamine aqueous solution, and chloroform were all purchased from Kanto Chemical (Tokyo, Japan) and used as received. The water used in this study was high-purity $\mathrm{H}_{2} \mathrm{O}$ (Milli-Q pure water; $R=18 \mathrm{M} \Omega$ $\mathrm{cm})$. An Au-coated microscope slide (Spectra-tech Co., Shelton, Connecticut) was used as a thin film for the $\mathrm{Au}$ evaporated on a glass slide. The gold-colored origami used in the study is commercially available in Japan.

\subsection{Measurements}

To identify the synthesized compound, a Bruker DPX400 spectrometer was used to measure the $400-\mathrm{MHz}^{1} \mathrm{H}-$ NMR spectra of the synthesized compounds at $30^{\circ} \mathrm{C}$; ESIMS measurements were performed using a Varian 910-M. The UV-vis absorption spectra were taken with a JASCO $\mathrm{V}-570$ spectrophotometer at $25^{\circ} \mathrm{C}$. The specular reflectance of the gold-colored materials was measured at room temperature (rt) using a JASCO V-570 spectrophotometer equipped with a JASCO ILN-472 integration sphere. XRD measurements were performed on a Rigaku diffractometer
$\mathrm{D} /$ teX Ultra using monochromated $\mathrm{Cu}-\mathrm{Ka}$ radiation $(44 \mathrm{kV}$, $50 \mathrm{~mA}$ ) at $25^{\circ} \mathrm{C}$. FT-IR spectra were recorded using a JASCO FT/IR 6100 spectrophotometer at a resolution of 4 $\mathrm{cm}^{-1}$ in the attenuated total reflection (ATR) mode (single reflection, incident angle $=45^{\circ}$, crystal ZnSe) at rt.

\subsection{Synthesis}

Azobenzene derivative 1 was synthesized according to Scheme 1. The synthesis of the 1 and intermediates 3 and 4 was reported by Iyi et al. ${ }^{8)}$ In this study, the synthetic procedure described by Iyi et al. was employed with some modifications. All the obtained compounds were identified by collating the ${ }^{1} \mathrm{H}-\mathrm{NMR}$ and MS spectra of the obtained compounds with the ${ }^{1} \mathrm{H}-\mathrm{NMR}$ and MS spectra reported in the literature ${ }^{8)}$.

2.3.1 Synthesis of intermediate (3).

To a mixture of $p$-aminophenol $(2.0 \mathrm{~g}, 18.3 \mathrm{mmol})$ in $20 \mathrm{ml}$ of water, $3 \mathrm{mM} \mathrm{HCl}$ aqueous solution $(30.3 \mathrm{ml}$ ) was added dropwise over $30 \mathrm{~min}$ at $\mathrm{rt}$; an aqueous solution $(108 \mathrm{~mL})$ of $\mathrm{NaNO}_{2}(1.3 \mathrm{~g}, 18.8 \mathrm{mmol})$ was then slowly added over 120 $\min$ at $0^{\circ} \mathrm{C}$. The reaction mixture was added dropwise to an aqueous solution consisting of water $(18.3 \mathrm{~mL}), \mathrm{CuSO}_{4}$. $5 \mathrm{H}_{2} \mathrm{O}(8.2 \mathrm{~g}, 32.8 \mathrm{mmol}), 28 \% \mathrm{NH}_{3}(5.5 \mathrm{~mL})$, and hydroxyammonium chloride $(1.3 \mathrm{~g}, 8.3 \mathrm{mmol})$. The reaction mixture was filtered, and the crude product was then washed with $1 \mathrm{M} \mathrm{HCl}$. Product 3 was obtained as a yellow solid when the crude product was recrystallized from a mixed acetone/water solvent. The yield was $1.4 \mathrm{~g}$ (71\%).

2.3.2 Synthesis of intermediate (4).

The reaction mixture of $3(0.20 \mathrm{~g}, 0.93 \mathrm{mmol}), \mathrm{K}_{2} \mathrm{CO}_{3}(0.90$ g, $6.5 \mathrm{mmol}), 1,2$-dibromoethane $(1.76 \mathrm{~g}, 9.37 \mathrm{mmol})$, and acetone $(25 \mathrm{~mL})$ was refluxed for $50 \mathrm{~h}$. After the reaction,

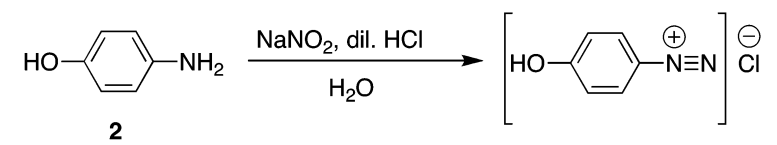

2
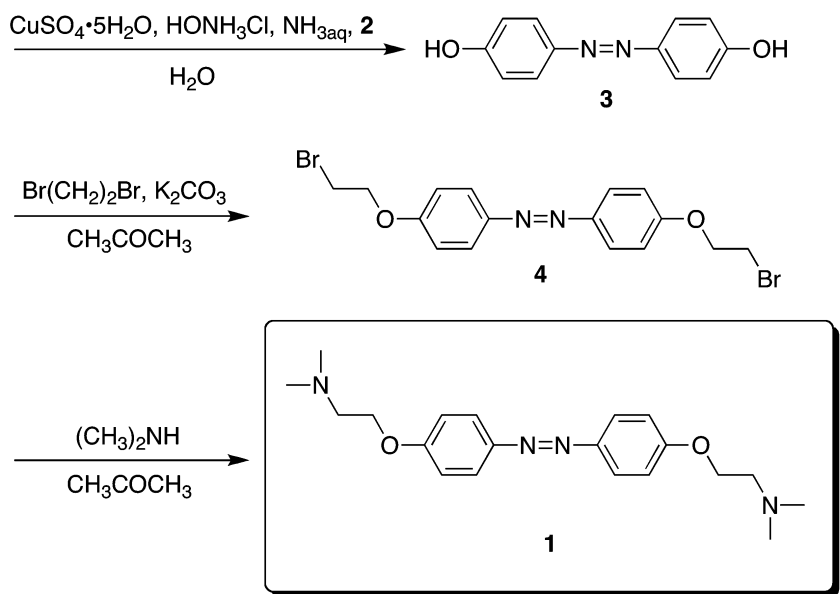

Scheme 1 
( a )

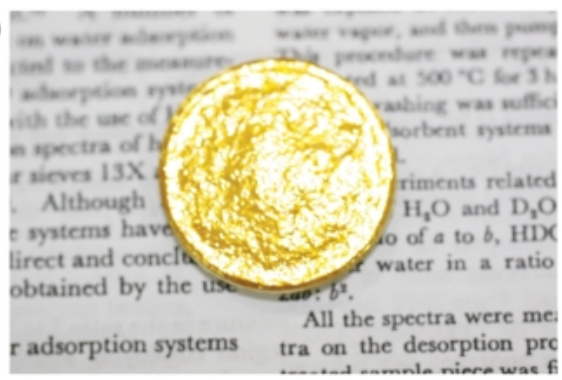

( b )

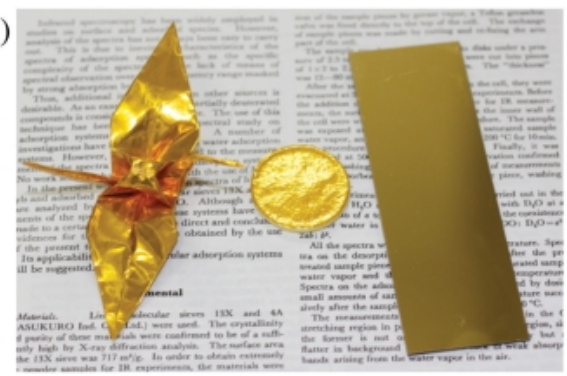

Fig. 1 Pictures of Gold-colored Materials.

(a) Crystals of $\mathbf{1}$ accumulated on a filter paper; (b) gold-colored origami folded into a crane (left), crystals of $\mathbf{1}$ piled up on a filter paper (center), and thin film of Au evaporated on a glass slide (right).
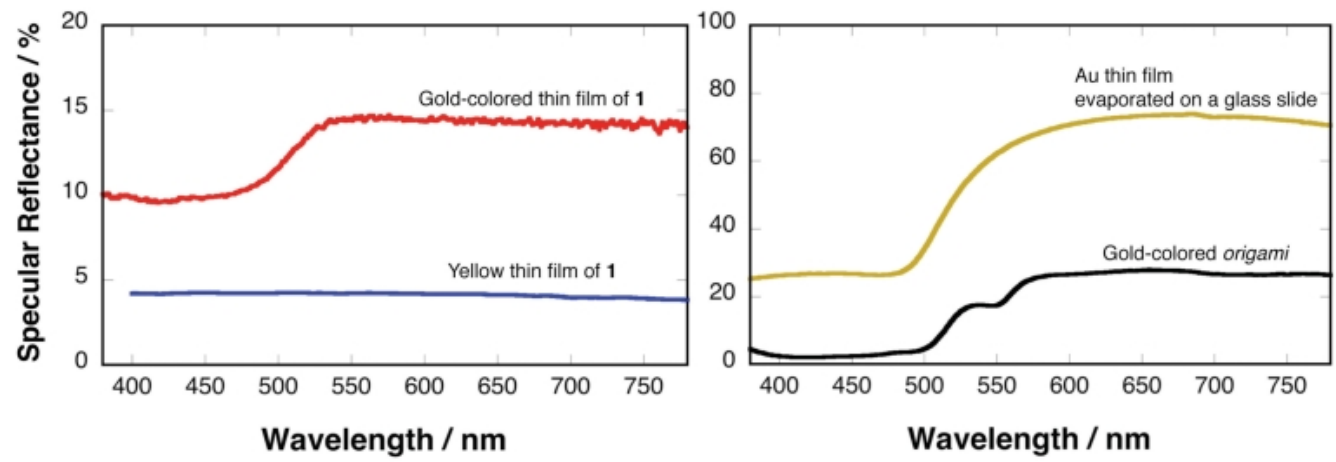

Fig. 2 Specular Reflections of the Thin Film of Gold-colored Crystals of 1 (red), Thin Film of Au Evaporated on a Glass Slide (ocher), Gold-colored Origami (black), and Yellow Thin Film of $\mathbf{1}$ (blue) That Was Obtained by Placing the Thin Film of the Gold-colored Crystals in a Dry Desiccator for $1 \mathrm{~d}$.

the solvent was evaporated and intermediate 4 was obtained as a yellow solid when the residue was repeatedly recrystallized from a mixed acetone/water solvent. The yield was $0.35 \mathrm{~g}$ (88\%).

2.3.3 Synthesis of the azobenzene derivative (1)

The reaction mixture of 4 ( $0.28 \mathrm{~g}, 0.65 \mathrm{mmol}), 40 \%$ aqueous solution of dimethylamine $(2.25 \mathrm{~mL}, 17.9 \mathrm{mmol})$, and acetone $(30 \mathrm{~mL})$ was stirred for $5 \mathrm{~d}$ at $\mathrm{rt}$. After the volatile components were removed by evaporation in vacuo, the residue was extracted using chloroform. The chloroform layer was evaporated to obtain the crude product. The azobenzene derivative (1) was obtained as a gold-colored solid by recrystallization of the crude product from a mixed acetone/water solvent, followed by drying under reduced pressure. The yield was $0.14 \mathrm{~g}(60 \%)$.

\section{RESULTS AND DISCUSSION}

Derivative 1 is easily soluble in acetone and methanol but insoluble in water. When a large amount $(100 \mathrm{~mL})$ of water was added to an acetone solution $(19 \mathrm{mM}, 60 \mathrm{~mL})$ of
1, gold-colored plate-like crystals $(\sim 15 \mathrm{~mm}$ length $\times \sim 15$ $\mathrm{mm}$ width) of 1 were precipitated. The crystals were recovered to obtain a thin film (thickness $\approx 0.3 \mathrm{~mm}$ ) on a filter paper through filtration. Figure 1 shows a thin film of the crystals of 1 recovered on the filter paper. As shown in the picture, the thin film has the same apparent color and luster as metallic gold $(\mathrm{Au})$ evaporated on a glass plate (Spectra-Tech Inc.) and gold-colored origami. The specular reflectance (incident light angle $=15^{\circ}$ ) of the thin film started to increase at $480 \mathrm{~nm}$ and leveled off above $520 \mathrm{~nm}$, producing a value of $15 \%$ in the range $520-780 \mathrm{~nm}$ (Fig. 2). Although the maximum specular reflectance (15\%) of the thin film was smaller than the reflectances of metallic gold and gold-colored origami, the curve obtained by plotting the specular reflectance against the wavelength of the thin film showed the same profile as the corresponding curves of the latter two, which means that the thin film has a gold luster. Iyi et al. reported that 1 is yellow in color ${ }^{8}$. Similarly, we obtained 1 as a yellow solid by evaporating acetone from the acetone solution of 1 . In addition, the gold-colored thin film of 1 turned to yellow when it was allowed to stand in a dry desiccator (humidity 40\%) for $1 \mathrm{~d}$. The specular 
reflectance of the yellow thin film was ca. $4 \%$ - which is smaller than that of the gold-colored thin film of 1 - over the range $400-780 \mathrm{~nm}$, indicating that the yellow film had almost no luster (Fig. 2).

Whereas the methanol solution $(0.1 \mathrm{mM})$ of 1 gave an absorption peak at $354 \mathrm{~nm}$ corresponding to the $\pi-\pi^{*}$ transition of the azobenzene moiety, the maximum absorption wavelength of the gold-colored plate-like crystals of 1 was $401 \mathrm{~nm}$, indicating a red shift (Fig. 3$)^{9)}$. These results indicate that 1 forms J-aggregates in the gold-colored crystals ${ }^{10}$. In contrast, the yellow crystals of 1 , which were prepared by placing the gold-colored crystals in a desiccator for $1 \mathrm{~d}$, showed a monotonous decrease in absorbance of UV-vis light with the wavelength and had no absorption peak over the range of 200-800 nm, indicating that the dryness of the gold-colored crystal results in the disruption of the J-aggregates.

Figure 4a shows X-ray diffraction (XRD) pattern for the gold-colored crystals of 1 . The largest diffraction peak was observed at $2 \theta=5.85^{\circ}$, and successive periodical diffrac-

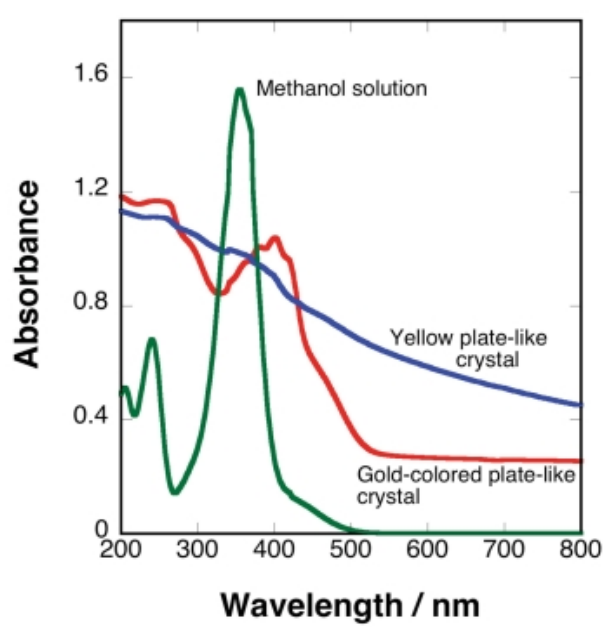

Fig. 3 UV-vis Absorption Spectra of 1 in Methanol (green), the Gold-colored Plate-like Crystal (red), and the Yellow Crystal (blue) Prepared by Placing the Gold-colored Crystal in a Desiccator for $1 \mathrm{~d}$.

( a )

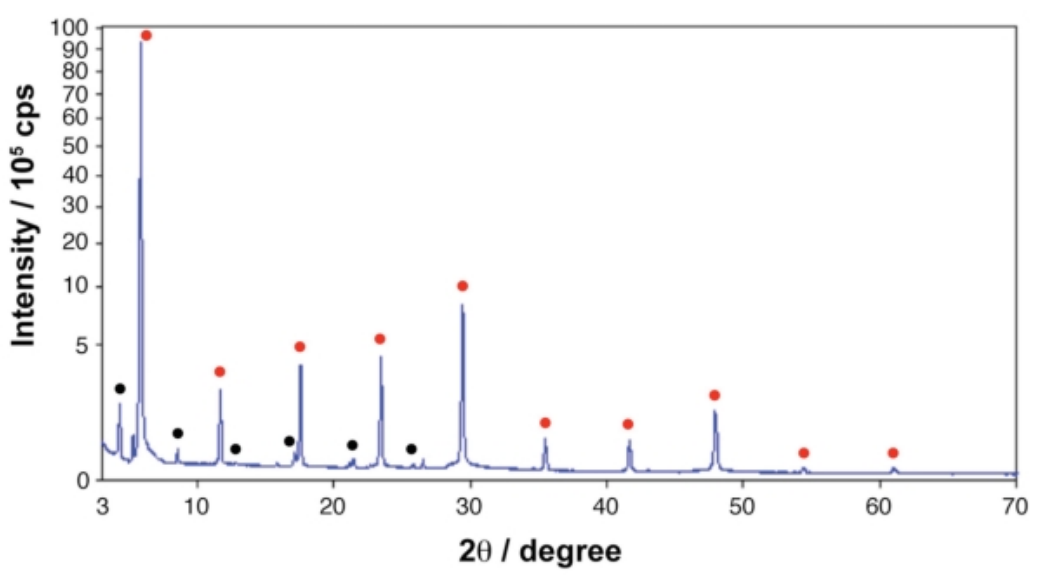

( b )

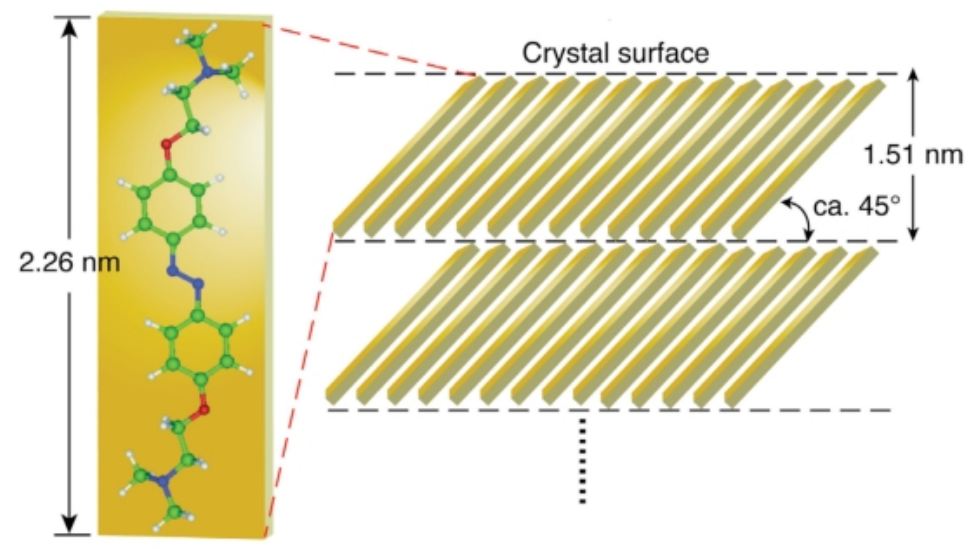

Fig. 4 (a)XRD Pattern of the Gold-colored Crystal. (b) Possible Orientation of $\mathbf{1}$ in the Gold-colored Crystal. 
tions up to the $10^{\text {th }}$ order (marked as red filled circles) showed a long-range $d$-spacing of $1.51 \mathrm{~nm}$; weaker periodic diffraction peaks $\left(2 \theta=4.29^{\circ}, d\right.$-spacing $\left.=2.06 \mathrm{~nm}\right)($ marked as black filled circles) were also observed. The gold-colored crystals of 1 were primarily formed by the stacking of 1.51$\mathrm{nm}$-thick molecular layers consisting of J-aggregates of 1 . The optimization of the molecular structure of 1 through MM2 calculations provided a molecular length of $2.26 \mathrm{~nm}$. As shown in Fig. 4b, 1 is oriented with the azobenzene moieties tilted by approximately $45^{\circ}$ against the gold-colored crystal surface to form J-aggregates. The resultant molecular orientation provides evidence of the existence of monolayers of 1 with a thickness of $1.51 \mathrm{~nm}$. A number of monolayers are stacked in the gold-colored crystals.

Figure 5 shows the FT-IR spectra for the gold-colored crystals and yellow crystals obtained by drying the goldcolored crystals in a desiccator for $1 \mathrm{~d}$. The spectrum for the gold-colored crystals showed a broad band in the range $3010-3680 \mathrm{~cm}^{-1}$, indicating that the crystal contains crystallized water molecules ${ }^{11}$, while the yellow crystal obtained by drying the gold-colored crystal in a desiccator exhibited no peak in the same range. Evaporation of the crystallized water molecules in the gold-colored crystal disrupted the J-aggregates formed from 1, changing its color from gold to yellow. In other words, crystallized water molecules play an important role in stabilizing J-aggregates in the goldcolored crystals. The crystallized water molecules will exhibit $\mathrm{H}$-bonding with the $\mathrm{N}$ atoms at both ends of 1 . The $\mathrm{H}$-bonding of $\left(\mathrm{CH}_{3}\right)_{2} \mathrm{~N} \cdots \mathrm{H}-\mathrm{O}-\mathrm{H} \cdots \mathrm{N}\left(\mathrm{CH}_{3}\right)_{2}$ may occur between two adjacent $\mathrm{N}\left(\mathrm{CH}_{3}\right)_{2}$ groups in each J-aggregate layer (intralayer H-bonding) or between two J-aggregate layers (interlayer $\mathrm{H}$-bonding). It is possible that such $\mathrm{H}^{-}$ bonding stabilizes J-aggregates in the gold-colored crystals.

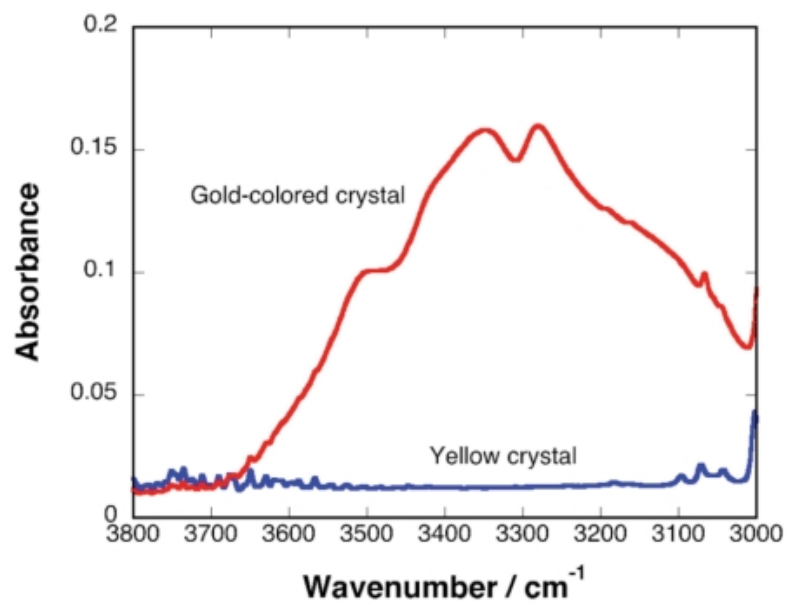

Fig. 5 FT-IR Spectra of the Gold-colored Crystal and Yellow Crystal.

\section{CONCLUSION}

We demonstrated here that the low MW organic compound 1 forms gold-colored crystals consisting of stacks of monolayers of J-aggregates that are structurally stabilized by crystallized water molecules; drying the crystals brings about a color change from gold to yellow, disrupts the Jaggregates, and lowers the specular reflectance of the crystals. This obvious decrease in the specular reflectance obtained by drying the gold-colored crystals may make it possible to utilize this crystal as a memory device. Studies are currently in progress to investigate the reversibility of the color change of the crystals and obtain further details on the orientation of 1 and water molecules in the crystals.

\section{ACKNOWLEDGEMENT}

This work was financially supported by KAKENHI (JSPS Grant-in-Aid for Scientific Research(C)) (21550182).

\section{References}

1. Mikulski, C.M.; Russo, P. J.; Saran, M.S.; MacDiarmid, A.G.; Garito, A.F.; Heeger, A.J. Synthesis and structure of metallic polymeric sulfur nitride, (SN)x, and its precursor, disulfur dinitiride, $\mathrm{S}_{2} \mathrm{~N}_{2}$. J. Am. Chem. Soc. 97, 6385-6363 (1975).

2. Ogura, K.; Zhao, R.; Yanai, H.; Maeda, K.; Tozawa, R.; Matsumoto, S.; Akazome, M. Facile formation of stable crystals with gold-like metallic luster from organic molecules: 1-Aryl-2-(2-thienyl)-5-[5-tricyanoethenyl)-2thienyl]pyrroles. Bull. Chem. Soc. Jpn. 75, 2359-2370 (2002).

3. Ogura, K.; Yanai, H.; Miokawa, M.; Akazome, M. A new $\pi$-system: 1-aryl-2,5-di(2-thienyl)pyrroles. Tetrahedron Lett. 40, 8887-8891 (1999).

4. Ogura, K.; Zhao, R.; Mizuoka, T.; Akazome, M.; Matsumoto, S. Formation of gold-like metal-lustrous inclusion crystals from 1-phenyl-2,5-bis[5-(tricyanoethenyl)2-trienyl]pyrrole host and an electron-donating aromatic guest. Org. Biomol. Chem. 1, 3845-3850 (2003).

5. Ogura, K.; Ooshima, K.; Akazome, M.; Matsumoto, S. Formation of metal-lustrous organic crystals from 2aryl-1-(4-methoxyphenyl)-5-(5-tricyanoethenyl-2thienyl)pyrroles. Tetrahedron 62, 2484-2491 (2006).

6. Sato, T.; Ozaki, Y.; Iriyama, K. Molecular aggregation and photoisomerization of Langmuir-Blodgett films of azobenzene-containing long-chain fatty acids and their salts studied by ultraviolet-visible and infrared spectroscopies. Langmuir 10, 2363-2369 (1994).

7. Matsumoto, M.; Miyazaki, D.; Tanaka, M.; Azumi, R.; Manda, E.; Kondo, Y.; Yoshino, N.; Tachibana, H. Reversible light-induced morphological change in 
Langmuir-Blodgett films. J. Am. Chem. Soc. 120, 14791484 (1998).

8. Iyi, N.; Fujita, T.; Yelamaggad, C. V.; Lopez Arbeloa, F. Intercalation of cationic azobenzene derivatives in a synthetic mica and their photoresponse. Appl. Clay Sci. 19, 47-58 (2001).

9. The UV-vis absorbance experiments were performed at $25^{\circ} \mathrm{C}$. A piece of the plate-like crystal (thickness $\approx 30$ $\mu \mathrm{m})$ of 1 was placed on a quartz slide, and it was used as a sample for the measurement. After the absorbance of the gold-colored crystal showed a maximum at 401 $\mathrm{nm}$, it decreased with wavelength and reached a con- stant value (0.26), not zero, above $520 \mathrm{~nm}$. The constant absorbance above $520 \mathrm{~nm}$ will result from the specular reflection of the gold-colored crystal surface.

10. Shimomura, M.; Kunitake, T. Fluorescence and photoisomerization of azobenzene-containing bilayer membranes. J. Am. Chem. Soc. 109, 5175-5183 (1987).

11. Kawai, T.; Umemura, J.; Takenaka, T.; Kodama, M.; Ogawa, Y.; Seki, S. Polarized fourier transform infrared spectra and molecular orientation of a water-dioctadecyldimethylammonium chloride system in the coagel and gel phases. Langmuir 2, 739-743 (1986). 